\title{
Oral administration of Brazilian propolis exerts estrogenic effect in ovariectomized rats
}

\author{
Yoshinori Okamoto', Takao Tobe' ${ }^{1}, K^{1}$ ji Ueda ${ }^{1}$, Tatsuyuki Takada² and Nakao Kojima ${ }^{1}$ \\ ${ }^{1}$ Faculty of Pharmacy, Meijo University, 150 Yagotoyama, Tempaku-ku, Nagoya 468-8503, Japan \\ ${ }^{2}$ Department of Pharmaceutical Sciences, Ritsumeikan University, \\ 1-1-1 Nojihigashi, Kusatsu, Shiga 525-8577, Japan
}

(Received October 24, 2014; Accepted January 16, 2015)

\begin{abstract}
Propolis, a natural product derived from plants by honeybees, is a mixture of several hundred chemicals, including flavonoids, coumaric acids, and caffeic acids, some of which show estrogen-like activity. In this study, the estrogenic activity of crude ethanolic extract of Brazilian propolis was determined using several in vitro and in vivo assays. Propolis was found to bind to human estrogen receptors (ERs). Furthermore, propolis induced the expression of estrogen-responsive genes in ERpositive MCF-7 and Ishikawa cells. These in vitro assays suggest that propolis exerts estrogenic activity; therefore, in vivo experiments were conducted using ovariectomized rats. Oral administration of propolis (55 or $550 \mathrm{mg} / \mathrm{kg} /$ day for 3 days) significantly increased uterine wet weight and luminal epithelium thickness in comparison with the corresponding values in the corn oil-treated control group. Moreover, propolis induced ductal cell proliferation in the mammary glands. These effects were completely inhibited by full ER antagonist ICI 182,780, confirming that the effects of propolis are mediated by the ER. Our data show that oral intake of propolis induces estrogenic activity in ER-expressing organs in vivo and suggest that Brazilian propolis is a useful dietary source of phytoestrogens and a promising treatment for postmenopausal symptoms.
\end{abstract}

Key words: Brazilian propolis, Phytoestrogens, Postmenopausal women, Natural products, Oral intake

\section{INTRODUCTION}

Estrogen plays a key role in a broad range of biological systems, including the reproductive system, the central nervous system, and metabolic systems. Decreased estrogen production in menopausal women leads to symptoms such as hot flush, insomnia, and osteoporosis. To relieve these menopausal symptoms, estrogen alone or in combination with progestin has been prescribed as estrogen or hormone replacement therapy (ERT or HRT) (Grodstein et al., 1997). Equine estrogens (equilin and equilenin) have also been used for postmenopausal women; however, equine and human estrogens induce several types of DNA lesions such as DNA oxidation and bulky DNA-adduct formation (Okamoto et al., 2008a, 2010; Okahashi et al., 2010). Accordingly, long-term treatment with estrogens has been reported to increase the incidence of breast cancer (Grodstein et al., 1997; Chlebowski et al., 2010; Beral et al., 2011). To improve quality of life for post- menopausal women, it is important that clinicians and researchers develop alternative ERT strategies that do not confer a significant risk of cancer.

Some natural products such as flavonoids have been reported to show estrogen receptor (ER)-mediated biological effects in several assays (Kuiper et al., 1998; Ito et al., 2006; Okamoto et al., 2006). Dietary intake of equol, a metabolite of the soybean isoflavone daidzein, prevented typical postmenopausal symptoms such as bone loss and fat accumulation in Japanese women because of its estrogenic potency (Ishimi, 2010). Genistein, a potent estrogenic isoflavone, has been reported to reduce postmenopausal symptoms in women (Taylor et al., 2009). In addition, daidzein and its active metabolite equol have an ability to suppress the proliferation of human breast cancer xenografts implanted in athymic nude mice (Liu et al., 2012). These reports suggest that phytoestrogens can be used for treatment of postmenopausal symptoms accompanied by cancer chemoprevention. 
Propolis is a resinous product that is derived from plants by honeybees for the purpose of sealing small gaps in the hive structure, and is distinct from beeswax. It has a long history of use as a folk medicine, and several biological effects of propolis such as anti-inflammatory, antimicrobial, anti-viral, and anti-oxidative activities have been reported (Burdock, 1998). Propolis contains several hundred chemicals, including flavonoids, coumaric acids, and caffeic acids, some of which are known to include estrogenic effects (Kuiper et al., 1998; van der Woude et al., 2005). Song et al. (2002) reported that subcutaneous administration of propolis showed estrogenic activity in immature rat. However, xenobiotics injected via subcutaneous route avoid first-pass metabolism as well as gastrointestinal absorption steps. For considering clinical use, propolis must be confirmed the estrogenic effectiveness by oral administration.

In the present study, the estrogenic activity of crude ethanolic extract of Brazilian propolis (EEP) was determined using several in vitro assays based on competitive binding to the ER and expression of estrogen inducible genes progesterone receptor (PR) and trefoil factor 1 (TFF-1; formerly $\mathrm{pS} 2$ ). We also determined the in vivo estrogenic activity of EEP via oral administration in ovariectomized (OVX) rats.

\section{MATERIALS AND METHODS}

\section{Chemicals}

Ethanolic extract of Brazilian propolis (EEP, 55\% $(\mathrm{w} / \mathrm{v})$ ) was a gift from Yamada Bee Farm Corp. (Okayama, Japan). 17 $\beta$-Estradiol (E2), corn oil, and dimethyl sulfoxide (DMSO) were purchased from Wako Pure Chemical Industries (Osaka, Japan). [2,4,6,7,16,17-3 H]17 $\beta$-Estradiol ( $\left.{ }^{3} \mathrm{H}-\mathrm{E} 2,161 \mathrm{Ci} / \mathrm{mmol}\right)$ was purchased from GE Health Care (Buckinghamshire, UK). ICI 182,780 was obtained from Tocris Bioscience (Ellisville, MO, USA).

\section{Estrogen receptor binding assay}

To determine the ER binding potency of EEP, the ER $\alpha$ and ER $\beta$ binding affinity of EEP was tested using a spin column assay with commercially available full-length hER $\alpha$ or hER $\beta$ (Life Technologies, Carlsbad, CA, USA) according to a previously reported method (Okamoto et al., 2008b). Briefly, various concentrations of EEP $\left(5.5 \times 10^{-4}\right.$ to $\left.55 \mu \mathrm{g} / \mathrm{mL}\right)$ were incubated at room temperature for $1 \mathrm{hr}$ in binding buffer containing hER $\alpha$ or hER $\beta$ $(1.5 \mathrm{nM})$ and ${ }^{3} \mathrm{H}$-labeled E2 $(1 \mathrm{nM})$. After incubation, the mixture was applied onto a macro spin column containing G-25 Sephadex (Harvard Apparatus, Holliston, MA, USA) according to the manufacturer's instructions. ER- bound ${ }^{3} \mathrm{H}-\mathrm{E} 2$ was separated from free ${ }^{3} \mathrm{H}-\mathrm{E} 2$ by gel filtration. The ER-bound ${ }^{3} \mathrm{H}-\mathrm{E} 2$ was dissolved in a scintillation cocktail (Nacalai, Kyoto, Japan) and radioactivity was counted using a scintillation counter (Hitachi Aloka Medical, Ltd., Tokyo, Japan). A binding curve was generated and $\mathrm{IC}_{50}$ value (the concentration that produced 50\% inhibition of ER-3 ${ }^{3}$-E2 binding) was calculated using a single binding site competition model and Prism 5 statistical analysis software (Graphpad Software, San Diego, CA, USA).

\section{Cell culture}

MCF-7 (breast cancer) and Ishikawa (endometrial cancer) ER-positive cancer cell lines were obtained from the European Collection of Cell Cultures (ECACC, Salisbury, UK). MCF-7 cells were maintained in Dulbecco's modified Eagle's medium (DMEM; Wako Pure Chemical Industries) supplemented with 10\% fetal bovine serum (FBS; Nichirei Biosciences, Tokyo, Japan), 1\% penicillin/streptomycin (Wako Pure Chemical Industries), and $2 \mathrm{mM}$ L-glutamine (Life Technologies), and cultured at $37^{\circ} \mathrm{C}$ under a humidified $5 \% \mathrm{CO}_{2}$ atmosphere. Ishikawa cells were maintained in DMEM supplemented with 5\% FBS, 1\% penicillin/streptomycin, and $2 \mathrm{mM}$ L-glutamine under the same atmospheric conditions as MCF-7 cells. Cells were plated onto a 24 -well culture plate at $5 \times 10^{4}$ cells/well and allowed to attach overnight. The next day, the medium was replaced with phenol red-free DMEM (Sigma-Aldrich, St. Louis, MO, USA) supplemented with 10\% charcoal-stripped FBS (Equitech Bio, Kerrville, TX, USA), 1\% penicillin/streptomycin, and $2 \mathrm{mM}$ L-glutamine, and incubated for a day. Test chemicals were dissolved in DMSO and applied to cells at final DMSO concentrations of less than $0.1 \%$. After $24 \mathrm{hr}$ of chemical treatment, cells were collected and used immediately in downstream assays or stored at $-80^{\circ} \mathrm{C}$ until use.

\section{Real-time quantitative PCR analysis}

Total RNA was isolated using a spin column (High Pure RNA Purification Kit, Roche Diagnostics, Indianapolis, IN, USA), and $500 \mathrm{ng}$ of total RNA was used as a template for first-strand cDNA synthesis using a kit (Primescript RT-PCR kit, Takara Bio, Shiga, Japan) according to the manufacturer's instructions. Real-time RT-PCR analysis was performed using SYBR green reagent (LightCycler 480 SYBR green I master, Roche Diagnostics). Primer pairs used for quantification of $P R, T F F-1$, and $G A P D H$ (glyceraldehyde-3-phosphate dehydrogenase, used as an internal standard) were as follows: $P R$ forward, 5'-TTTAAGAGGGCAATGGAAGG-3'; $P R$ reverse, 5'-CGGATTTTATCAACGATGCAG-3'; $T F F-1$ for- 
Estrogenic effect of Brazilian propolis

ward, 5'-CCCTCCCAGTGTGCAAAT-3'; TFF-1 reverse, 5'-GATCCCTGCAGAAGTGTCTAAAA-3'; GAPDH forward, 5'-AGCCACATCGCTCAGACAC-3', GAPDH reverse, 5'-GCCCAATACGACCAAATCC-3'. All reactions and data analysis were performed using a LightCycler 480 system II and its accompanying software (Roche Diagnostics). All reactions were performed in duplicate. Results are shown as the mean \pm S.E.M. of 3 independent experiments. The $P R$ and $T F F-1$ levels were normalized to the $G A P D H$ level for the corresponding treatment.

\section{Animal experiments and sample collection}

All animal experiments were conducted in compliance with the Animal Experiment Guidelines of Meijo University. Sprague-Dawley rats (4-week-old females; Japan SLC, Shizuoka, Japan) were ovariectomized by the animal vendor. The rats were given water and standard pellet feed ad libitum, and were kept on a 12-hr light/ dark cycle throughout the study. After a week of acclimation, 15 rats were divided into 5 groups (3 rats/group). EEP was administered by gavage for 3 days at a dosage of 55 or $550 \mathrm{mg} / \mathrm{kg} /$ day. For the experiments to confirm the ER-mediated effect of EEP, rats were pre-treated orally with ICI 182,780 ( $1 \mathrm{mg} / \mathrm{kg} /$ day $) 1 \mathrm{hr}$ before every EEP treatment. As a positive control, E2 $(0.3 \mu \mathrm{g} / \mathrm{kg} /$ day $)$ was administered subcutaneously. All compounds were dissolved in corn oil and the negative control group was orally administered $1 \mathrm{~mL} / \mathrm{kg}$ /day corn oil. No significant change in body weight was observed during the experimental period. The uterus and the 4th mammary gland were collected $24 \mathrm{hr}$ after the final compound administration. Uterine wet weight was recorded, and the uterus and mammary gland were fixed in $10 \%$ phosphate-buffered formalin and used for histopathological analysis.

\section{Histopathological analysis}

Whole mounts of mammary gland were prepared as previously reported (Okamoto et al., 2010). Briefly, fixed 4 th mammary glands were dissected free from the skin and processed as a whole mount. The glands were defatted in ethanol, acetone, chloroform, and ethanol again for at least 3 days in each solvent. After rehydration, the glands were stained with hematoxylin, cleaned up under a stereomicroscope, dehydrated in ethanol, cleared in xylene, and mounted. Images were taken under a stereomicroscope (Stemi SV11, Carl Zeiss, Jena, Germany) equipped with a digital camera.

Mammary whole mounts were used to prepare paraffin-fixed mammary sections. Paraffin-embedded glands were sliced using a microtome (thickness, $5 \mu \mathrm{m}$ ), and antigen retrieval was carried in an autoclave at $121^{\circ} \mathrm{C}$ for $15 \mathrm{~min}$. The sections were pretreated with $0.5 \%$ $\mathrm{H}_{2} \mathrm{O}_{2}$, blocked with 5\% skim milk, and incubated with anti-Ki67 primary antibodies (1:100; ab16667, Abcam, Cambridge, MA, USA) in phosphate-buffered saline with Tween 20 overnight at room temperature. Sections were treated with horseradish peroxidase-conjugated secondary antibodies (1:1,000; ab6721, Abcam) for $2 \mathrm{hr}$ at room temperature. Peroxidase labeling was visualized using 3,3'-diaminobenzidine tetrahydrochloride staining kit (Nichirei Biosciences) according to the manufacturer's instruction. When a dark brown color developed, sections were stained with hematoxylin and eosin (H\&E) and mounted on glass slides. Images were captured under a digital microscope (BZ-9000, Keyence, Osaka, Japan), and Ki67-positive and -negative cells in the mammary epithelium were counted by 2 independent investigators (at least 100 cells were counted in each section). The percentage of Ki67-positive cells out of the total mammary epithelial cells was taken as a measure of the potency of estrogenic activity.

Fixed uterine tissues were embedded in paraffin. The sections were prepared at a thickness of $5 \mu \mathrm{m}$, stained with $\mathrm{H} \& \mathrm{E}$, and mounted on glass slides. Images were captured under a digital microscope (Keyence) and the thickness of the uterine luminal epithelium was measured using analytical software (Keyence). Pathological evaluation was carried out by 2 independent investigators.

\section{High-resolution QTOF mass spectrometry}

Non-target analysis was carried out to estimate the structure of estrogenic compounds in Brazilian propolis. High-resolution mass spectra were acquired using a quadrupole time-of-flight (QTOF) mass spectrometer (Impact HD, Bruker Daltonics Inc., Billerica, MA, USA) equipped with an HPLC system (Nexera, Shimadzu, Kyoto, Japan). Mass spectral conditions were as follows: ion source, electro-chemical ionization; nebulizer gas, 2.0 bar; dry gas, $8.0 \mathrm{~L} / \mathrm{min}$; dry temperature, $200^{\circ} \mathrm{C}$; and ion polarity, positive mode. HPLC separation was carried out using the following conditions: column, ODS (2.0 i.d. x $150 \mathrm{~mm}$, $3 \mu \mathrm{m}$ ); column oven, $40^{\circ} \mathrm{C}$; mobile phase $\mathrm{A} / \mathrm{B}, 0.1 \%$ for$\mathrm{mic}$ acid/methanol; A/B gradient program, linear from $100 / 0$ to $0 / 100$ over $60 \mathrm{~min}$; flow rate, $0.2 \mathrm{~mL} / \mathrm{min}$, and injection volume, $1 \mu \mathrm{L}$. EEP was diluted 100 -fold with methanol before it was applied to the high-resolution LCQTOF system. Data analysis was performed on TargetAnalysis software (Bruker Daltonics Inc.).

\section{Statistical analysis}

Each experiment was repeated at least three times. The values are expressed as the mean value \pm S.D. The 
significance of the differences between mean values were assessed using Student's $t$-test. All computations were calculated using the Microsoft Excel program.

\section{RESULTS}

\section{ER-binding potency}

Because ligand binding to ER is the primary mediator of the action of estrogens, a competitive ER binding assay using ${ }^{3} \mathrm{H}$-labeled $\mathrm{E} 2$ was carried out to determine the ER-binding potency of EEP. As shown in Fig. 1, EEP competitively bound to both ERs. The $\mathrm{IC}_{50}$ value of EEP for $\mathrm{hER} \alpha$ was $96.8 \mu \mathrm{g} / \mathrm{mL}$, and the $\mathrm{IC}_{50}$ value of $\mathrm{EEP}$ for $\mathrm{hER} \beta$ was $15.3 \mu \mathrm{g} / \mathrm{mL}$. This assay showed that EEP was about 6 times as potent at the hER $\beta$ in comparison with its potency at the $\mathrm{hER} \alpha$.

\section{Estrogen-inducible gene expression}

After ligand binding, ER agonists promote the expression of estrogen-inducible genes such as $P R$ and TFF-1. Using ER-positive human breast cancer MCF-7 cells and endometrial cancer Ishikawa cells, $P R$ and $T F F-1$ expression was determined using real-time quantitative PCR analysis (Fig. 2). In MCF-7 and Ishikawa cells, EEP induced the expression of estrogen-inducible genes at the highest concentration used in this study $(5.5 \mu \mathrm{g} / \mathrm{mL})$.



Fig. 1. hER $\alpha$ and hER $\beta$ binding affinity of EEP. ER binding affinity was determined using a spin column assay as described in the Materials and Methods. EEP (5.5 $\times$ $10^{-4}$ to $\left.55 \mu \mathrm{g} / \mathrm{mL}\right)$ was incubated in a buffer containing hER $\alpha$ or $\beta(1.5 \mathrm{nM})$ and ${ }^{3} \mathrm{H}-\mathrm{E} 2(1 \mathrm{nM})$ at $37^{\circ} \mathrm{C}$ for $1 \mathrm{hr}$. To separate bound E2, the reaction mixture was applied to a macro spin column containing G-25 Sephadex, and the flow-through was used for measurement of radioactivity counting using a liquid scintillation counter. A binding curve was fitted using a single binding site competition model and Prism statistical analysis software.
Estrogenic effect on mammary gland in OVX rats

In order to confirm the estrogenic effect of EEP in vivo, OVX rats were treated with 55 or $550 \mathrm{mg} / \mathrm{kg}$ EEP by gavage for 3 days. E2 $(0.3 \mu \mathrm{g} / \mathrm{kg}$, s.c. $)$ was administered as a positive control. Whole-mount analysis clearly showed the development of mammary lobuli and ducts in the E2-treated rats (Fig. 3c). However, little or no difference was seen in the EEP $(550 \mathrm{mg} / \mathrm{kg})$ treated rats in comparison with the control group (Fig. 3a and $3 b$ ). To evaluate EEP-induced cell proliferation, paraffin-fixed mammary gland sections were prepared and the expression of cell proliferation marker Ki67 antigen in the mammary epithelium was determined by immunostaining analysis (Fig. 3d). In the E2-treated $(0.3 \mu \mathrm{g} / \mathrm{kg})$ group, $79.5 \%$ of the mammary epithelial cells were Ki67positive, whereas in the control group, $8.8 \%$ of the mammary epithelial cells were Ki67-positive. Oral EEP treatment increased the percentage of Ki67-positive cells in a dose-dependent manner ( $15.1 \%$ by treatment with $55 \mathrm{mg} / \mathrm{kg}$ and $33.2 \%$ by treatment with $550 \mathrm{mg} / \mathrm{kg}$ ). In addition, pretreatment with ICI 182,780 $(1 \mathrm{mg} / \mathrm{kg})$ diminished the increase in Ki67-positive cells observed in the group treated with a high dose $(550 \mathrm{mg} / \mathrm{kg})$ of EEP.

\section{Estrogenic effect of EEP in the OVX rat uterus}

The estrogenic effect of EEP in the uterus was determined based on EEP-induced increases in uterine wet weight and epithelial thickness. In comparison with the control treatment, E2 $(0.3 \mu \mathrm{g} / \mathrm{kg})$ treatment increased uterine wet weight and epithelial thickness by 3.98- and 3.34-fold (Fig. 4). In the EEP-treated rats, uterine wet weight and epithelial thickness significantly increased in a dose-dependent manner. In comparison with the control treatment, EEP at a dose of 55 and $550 \mathrm{mg} / \mathrm{kg}$ increased uterine wet weight 1.40- and 1.81-fold, respectively, and increased uterine epithelial thickness 1.27- and 1.34-fold, respectively. The effects of EEP on uterine wet weight and epithelial thickness were completely suppressed by pretreatment with ICI 182,780.

\section{Determination of the estrogenic constituents of Brazilian propolis}

To evaluate the active estrogenic constituents of Brazilian propolis, non-target mass spectrometry analysis was performed using a high-resolution QTOF mass spectrometer (Fig. 5). The base peak chromatogram showed that EEP contained a large number of compounds (Fig. 5a). As shown in Fig. 5b, high-resolution extracted ion chromatograms indicated the existence of compounds with molecular weights $\left([\mathrm{M}+\mathrm{H}]^{+} \pm 0.002\right.$ mass units) equivalent to those reported for phytoestrogens for- 
Estrogenic effect of Brazilian propolis

\section{A MCF-7 cells}

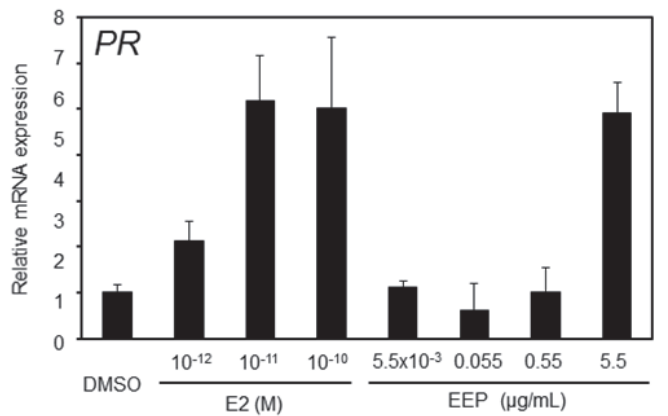

B Ishikawa cells

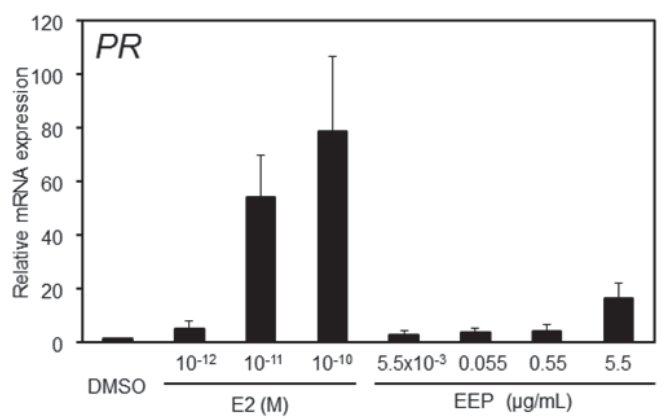

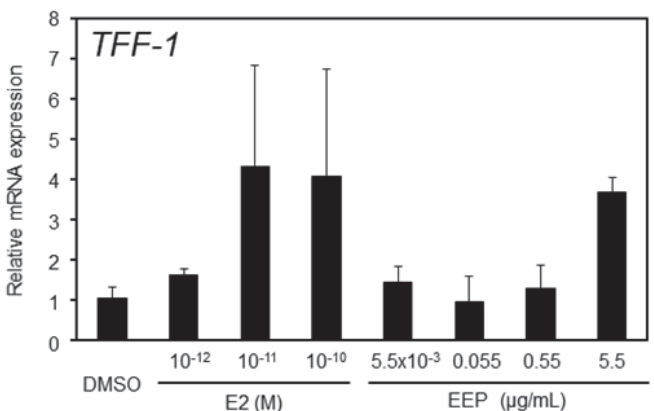

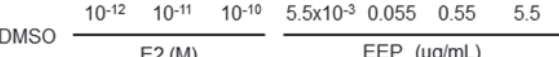

Fig. 2. Effect of EEP on E2-inducible gene expression in MCF-7 and Ishikawa cells. Human breast cancer MCF-7 cells (A) and endometrial Ishikawa cells (B) were exposed for $24 \mathrm{hr}$ to EEP $\left(5.5 \times 10^{-3}\right.$ to $\left.5.5 \mu \mathrm{g} / \mathrm{mL}\right)$ in phenol red-free DMEM containing $10 \%$ charcoal-stripped FBS, $1 \%$ penicillin/streptomycin, and $2 \mathrm{mM} \mathrm{L-glutamine.} P R$ and $T F F-1$ gene expression was determined by real-time quantitative PCR analysis as described in the Materials and Methods. Gene expression was normalized to GAPDH expression. Data are expressed as mean \pm S.E.M. $(\mathrm{n}>3)$.

\section{A Corn oil}
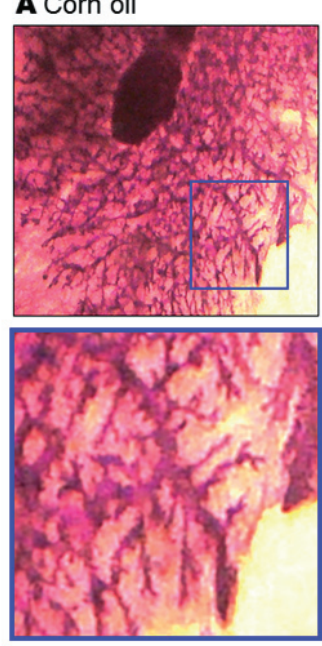


\section{E2 $(0.3 \mu \mathrm{g} / \mathrm{kg})$}
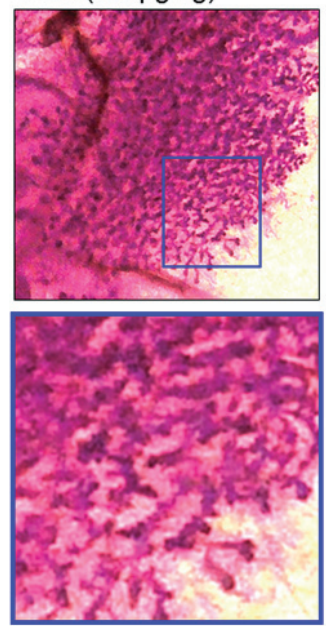

D

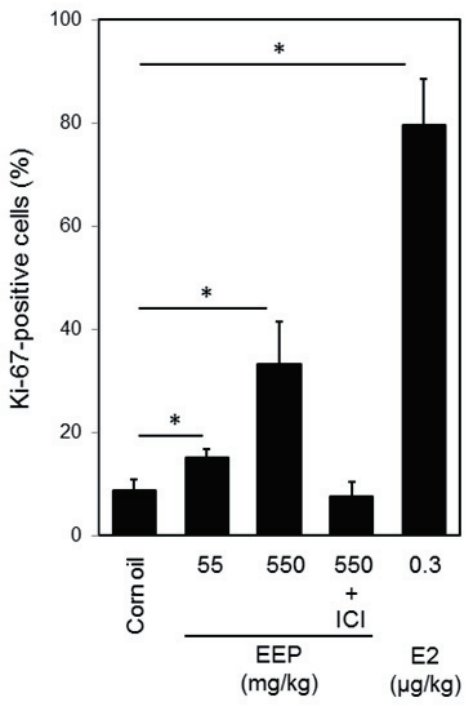

Fig. 3. Effect of EEP on mammary gland histology in OVX rats. A-C, Images $(30 \times$ magnification $)$ of whole mount preparations of mammary glands from OVX rats treated with corn oil, EEP $(550 \mathrm{mg} / \mathrm{kg}$, p.o.), or E2 $(0.3 \mu \mathrm{g} / \mathrm{mL}$, s.c.). D, Percentages of Ki67-positive cells in mammary epithelium. Data are expressed as mean \pm S.D. $(n>3)$. 
A

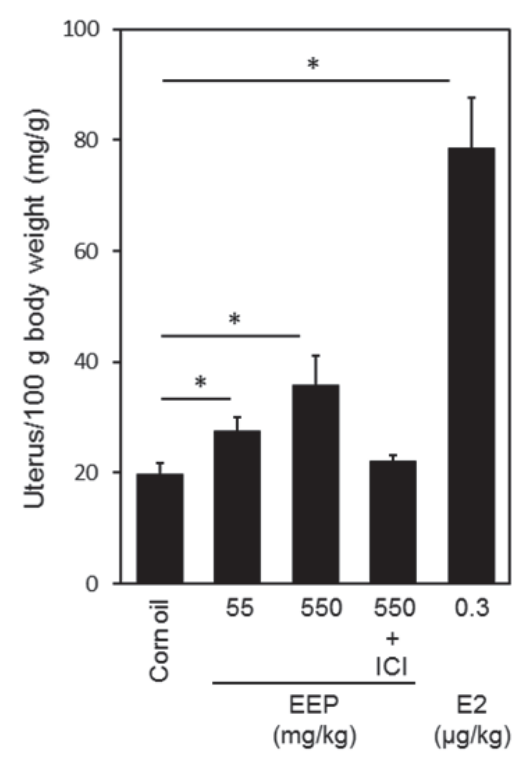

B

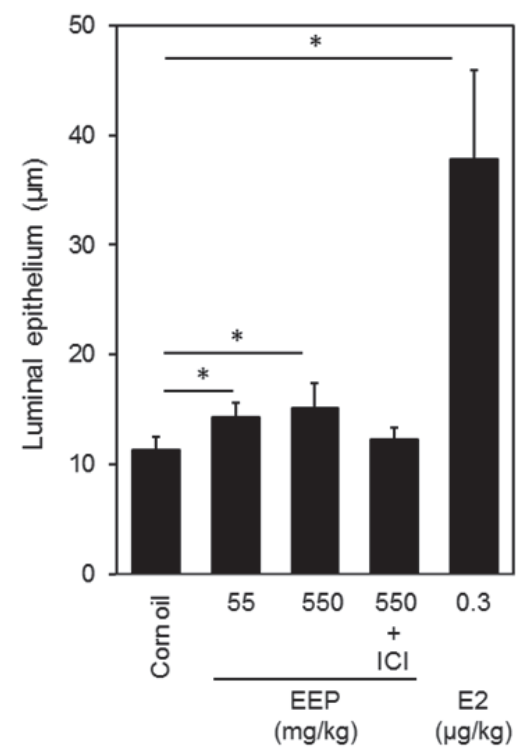

Fig. 4. Effect of EEP on uterine wet weight and luminal epithelium thickness in OVX rats. A, Uterine wet weight; B, luminal epithelium thickness. Data are expressed as mean \pm S.D. $(n>3)$.

mononetin $(\mathrm{m} / \mathrm{z} 269.0814)$, naringenin $(\mathrm{m} / \mathrm{z} 273.0763)$, biochanin A ( $\mathrm{m} / \mathrm{z} 285.0763)$, kaempferol $(\mathrm{m} / \mathrm{z} 287.0556)$, and quercetin $(\mathrm{m} / \mathrm{z} 303.0505)$.

\section{DISCUSSION}

Propolis contains hundreds of phenolic compounds and is thus an attractive source of bioactive materials such as phytoestrogens for prevention of post-menopausal symptoms. Song et al. (2002) reported that Korean propolis showed estrogenic activity based on rat uterotrophic assay in which ethanolic or ether extracts of Korean propolis were subcutaneously administered to immature Sprague-Dawley rats (20-21 days old). Oral administration would be the most suitable route of propolis administration in humans, and its absorption and metabolism should be considered in the context of the gastrointestinal tract. In the present study, we demonstrated that EEP exerts estrogenic action in OVX rats (5 weeks old) at doses of 55 and $550 \mathrm{mg} / \mathrm{kg} /$ day (equivalent to 3.3 and $33 \mathrm{~g} /$ day, respectively, for a $60 \mathrm{~kg}$ person) via oral administration. This effect would be induced by compounds containing in EEP, because EEP showed estrogenic activity in several in vitro assays. Although immature rats are sensitive to E2 and genistein, a representative estrogenic flavonoid, in comparison with mature OVX rats (Tinwell et al., 2000; Kanno et al., 2003), Korean propolis needed about 10 -fold higher dosage $(500 \mathrm{mg} / \mathrm{kg} /$ day) than Brazilian propolis to increase uterine weight. Therefore, the estrogenic potency of Brazilian propolis would be expected to be stronger than that of Korean propolis reported by Song et al. (2002). It is expected that differences in the effects of Brazilian and Korean propolis would be due to differences in their constituent compounds and/or metabolic activation of constituent compounds via a first-pass metabolic effect.

Several groups have identified bioactive components of propolis (Shimizu et al., 2004; Li et al., 2007; Szliszka et al., 2011), including phytoestrogens kaempferol, naringenin, and quercetin (Kuiper et al., 1998; van der Woude et al., 2005). Although the estrogenic components of the EEP used in this study have not been identified, our preliminary experiments utilizing a high-resolution QTOFmass spectrometer indicated that EEP contained known phytoestrogens kaempferol, quercetin, naringenin, biochanin A (4'-O-methyl-genistein), and formononetin (4'-O-methyl-daidzein) (Fig. 5). Kaempferol, quercetin, and naringenin have low bioavailability because of their hydrophilicity. In contrast to kaempferol, quercetin, and naringenin, biochanin $\mathrm{A}$ and formononetin are relatively lipophilic and exert estrogenic activity via metabolic 4'-O-demethylation (Tolleson et al., 2002). Therefore, 
Estrogenic effect of Brazilian propolis

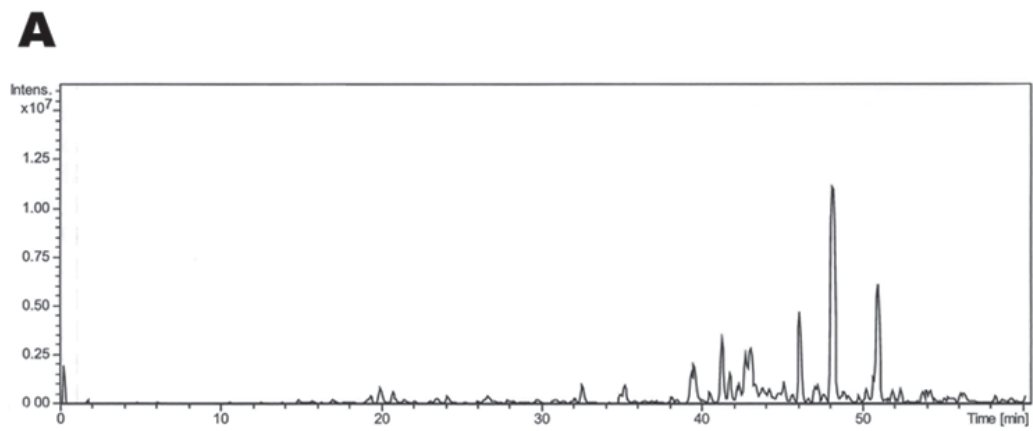

B

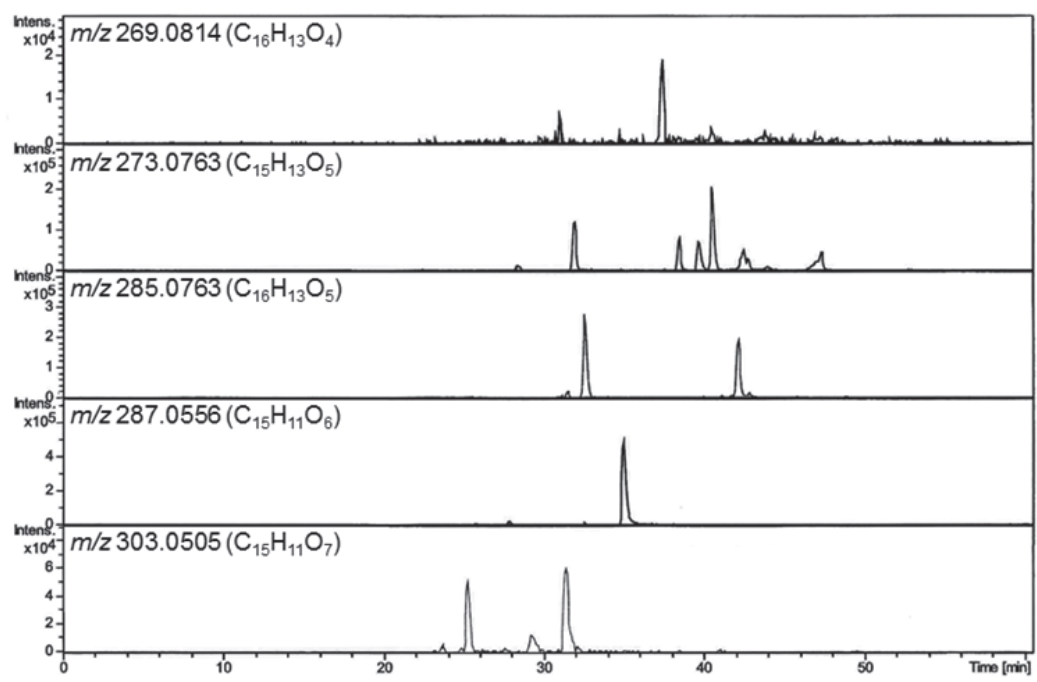

Fig. 5. High-resolution LC-QTOF mass spectra of EEP. A, Base peak chromatogram; B, high-resolution extracted ion chromatograms.

lipophilic phytoestrogens would contribute to the estrogenic activity of EEP in OVX rats.

Natural estrogens and equine estrogens are currently prescribed to postmenopausal women, but these potent estrogens exert severe side effects, such as increased cancer risk, and thus alternative estrogens are needed to support continued treatment of such patients. Although further experiments must be conducted, our data suggest that oral intake of propolis produces estrogenic activity in estrogen target organs in vivo. Therefore, Brazilian propolis represents a useful dietary source of phytoestrogens and a promising treatment for postmenopausal symptoms.

Conflict of interest---- The authors declare that there is no conflict of interest.

\section{ACKNOWLEDGMENTS}

This work was supported in part by Grants-in-Aid for Scientific Research from the Ministry of Education, Culture, Sports, Science and Technology of Japan and by Yamada Research Grant. We thank the past-laboratory members who worked on this project.

\section{REFERENCES}

Beral, V., Reeves, G., Bull, D. and Green, J., for the Million Women Study Collaborators. (2011): Breast cancer risk in relation to the interval between menopause and starting hormone therapy. J. Natl. Cancer Inst., 103, 296-305.

Burdock, G.A. (1998): Review of the biological properties and toxicity of bee propolis (propolis). Food Chem. Toxicol., 36 347363.

Chlebowski, R.T., Anderson, G.L., Gass, M., Lane, D.S., Aragaki, A.K., Kuller, L.H., Manson, J.E., Stefanick, M.L., Ockene, J., Sarto, G.E., Johnson, K.C., Wactawski-Wende, J., Ravdin, 
P.M., Schenken, R., Hendrix, S.L., Rajkovic, A., Rohan, T.E., Yasmeen, S. and Prentice, R.L., for the WHI Investigators, (2010): Estrogen plus progestin and breast cancer incidence and mortality in postmenopausal women. JAMA, 304, 1684-1692.

Grodstein, F., Stampfer, M.J., Colditz, G.A., Willett, W.C., Manson, J.E., Joffe, M., Rosner, B., Fuchs, C., Hankinson, S.E., Hunter, D.J., Hennekens, C.H. and Speizer, F.E. (1997): Postmenopausal hormone therapy and mortality. N. Engl. J. Med., 336, 17691775.

Ishimi, Y. (2010): Dietary equol and bone metabolism in postmenopausal Japanese women and osteoporotic mice. J. Nutr., 140, 1373S-1376S.

Ito, C., Itoigawa, M., Kumagaya, M., Okamoto, Y., Ueda, K., Nishihara, T., Kojima, N. and Furukawa, H. (2006): Isoflavonoids with antiestrogenic activity from Millettia pachycarpa. J. Nat. Prod., 69, 138-141.

Kanno, J., Onyon, L., Peddada, S., Ashby, J., Jacob, E. and Owens, W. (2003): The OECD program to validate the rat uterotrophic bioassay. Phase 2: dose-response studies. Environ. Health Perspect., 111, 1530-1549.

Kuiper, G.G., Lemmen, J.G., Carlsson, B., Corton, J.C., Safe, S.H., van der Saag, P.T., van der Burg, B. and Gustafsson, J.Å. (1998): Interaction of estrogenic chemicals and phytoestrogens with estrogen receptor $\beta$. Endocrinology, 139, 4252-4263.

Li, H., Kapur, A., Yang, J.X., Srivastava, S., McLeod, D.G., Paredes-Guzman, J.F., Daugsch, A., Park, Y.K. and Rhim, J.S. (2007): Antiproliferation of human prostate cancer cells by ethanolic extracts of Brazilian propolis and its botanical origin. Int. J. Oncol., 31, 601-606.

Liu, X., Suzuki, N., Laxmi, Y.R.S., Okamoto, Y. and Shibutani, S. (2012): Anti-breast cancer potential of daidzein in rodents. Life Sci., 91, 415-419.

Okahashi, Y., Iwamoto, T., Suzuki, N., Shibutani, S., Sugiura, S., Itoh, S., Nishiwaki, T., Ueno, S. and Mori, T. (2010): Quantitative detection of 4-hydroxyequilenin-DNA adducts in mammalian cells using an immunoassay with a novel monoclonal antibody. Nucleic Acids Res., 38, e133.

Okamoto, Y., Suzuki, A., Ueda, K., Ito, C., Itoigawa, M., Furukawa, H., Nishihara, T. and Kojima, N. (2006): Anti-estrogenic activity of prenylated isoflavones from Millettia pachycarpa: Impli- cations for pharmacophores and unique mechanisms. J. Health Sci., 52, 186-191.

Okamoto, Y., Chou, P.H., Kim, S.Y., Suzuki, N., Laxmi, Y.R.S., Okamoto, K., Liu, X., Matsuda, T. and Shibutani, S. (2008a): Oxidative DNA damage in $X P C$-knockout and its wild mice treated with equine estrogen. Chem. Res. Toxicol., 21, 11201124.

Okamoto, Y., Liu, X., Suzuki, N., Okamoto, K., Sekimoto, M., Laxmi, Y.R.S. and Shibutani, S. (2008b) Increased antitumor potential of the raloxifene prodrug, raloxifene diphosphate. Int. J. Cancer, 122, 2142-2147.

Okamoto, Y., Liu, X., Suzuki, N., Okamoto, K., Kim, H.J., Laxmi, Y.R.S., Sayama, K. and Shibutani, S. (2010): Equine estrogeninduced mammary tumors in rats. Toxicol. Lett., 193, 224-228.

Shimizu, K., Ashida, H., Matsuura, Y. and Kanazawa, K. (2004): Antioxidative bioavailability of artepillin $\mathrm{C}$ in Brazilian propolis. Arch. Biochem. Biophys., 424, 181-188.

Song, Y.S., Jin, C., Jung, K.J. and Park, E.H. (2002): Estrogenic effects of ethanol and ether extracts of propolis. J. Ethnopharmacol., 82, 89-95.

Szliszka, E., Zydowicz, G., Janoszka, B., Dobosz, C., KowalczykZiomek, G. and Krol, W. (2011): Ethanolic extract of Brazilian green propolis sensitizes prostate cancer cells to TRAIL-induced apoptosis. Int. J. Oncol., 38, 941-953.

Taylor, C.K., Levy, R.M., Elliott, J.C. and Burnett, B.P. (2009): The effect of genistein aglycone on cancer and cancer risk: a review of in vitro, preclinical, and clinical studies. Nutr. Rev., 67, 398415.

Tinwell, H., Soames, A.R., Foster, J.R. and Ashby, J. (2000): Estradiol-type activity of coumestrol in mature and immature ovariectomized rat uterotrophic assays. Environ. Health Perspect., 108, 631-634.

Tolleson, W.H., Doerge, D.R., Churchwell, M.I., Marques, M.M. and Roberts, D.W. (2002): Metabolism of biochanin A and formononetin by human liver microsomes in vitro. J. Agric. Food Chem., 50, 4783-4790.

van der Woude, H., ter Veld, M.G.R., Jacobs, N., van der Saag, P.T., Murk, A.J. and Rietjens, I.M.C.M. (2005): The stimulation of cell proliferation by quercetin is mediated by the estrogen receptor. Mol. Nutr. Food Res., 49, 763-771. 